\title{
Megaeventos: uma estratégia de atração turística?
}

\section{Mega events: a tourist attraction strategy?}

\author{
Bruno Alberini (ALBERINI, B.) ${ }^{*}$
}

RESUMO - Os megaeventos têm sido reconhecidos como elementos dos mais dinâmicos para o incremento do turismo em localidades ou países. O objetivo do presente artigo foi o de investigar como a produção de megaeventos, associada a relações internacionais, pode contribuir para a promoção da imagem dos países que os sediam, potencializando a atratividade turística internacional. Como base teórica referencial utilizou-se a Copa do Mundo de Futebol da FIFA (Fédération Internationale de Football Association). Em sua construção se fez uso de pesquisa exploratória baseada em publicações impressas e em sítios eletrônicos. Como resultado verificou-se que os megaeventos podem contribuir para a promoção da imagem dos países que os sediam, potencializando a atratividade turística internacional.

Palavras chave: Megaeventos; Estratégias; Atratividade turística; Copa do Mundo de Futebol.

ABSTRACT - The mega events have been recognized as the most dynamic elements to the growth of tourism in localities or countries. The objective of this paper was to investigate how the production of mega events associated to international relations, can contribute to promoting the image of the countries that host them, increasing international tourist attractiveness. As theoretical referential basis was used the Fifa (Fédération Internationale de Football Association) World Cup. In its construction it was used exploratory research based on printed publications and electronic sites. As a result it was found that mega events can contribute to promote the image of the countries that host them, increasing international tourist attractiveness.

Key words: Megaeventos; Strategies; Tourist attractiveness; World Cup Football.

\footnotetext{
* Formação: Graduação em Turismo (Bacharelado) pela Universidade Federal do Paraná (UFPR), Especialização em Marketing pelo Centro Universitário FAE Business School. Atividade profissional: Analista de Comunicação da Global Village Telecom - GVT. Endereço físico para correspondência: Rua Pasteur, 767, ap. 601, Batel. CEP: 80250-080 - Curitiba - Paraná (Brasil). Telefone para contato: (41) 9632-6689. E-mail: brunoalberini@gmail.com
} 


\section{INTRODUÇÃO}

O segmento do turismo de eventos inserido na gestão turística pode contribuir para a difusão de estratégias capazes de atrair grandes demandas de turistas e evitar o fenômeno da sazonalidade. Neste contexto, no presente artigo visou-se analisar como a produção de megaeventos, associada a relações internacionais, poderia contribuir para a promoção da imagem dos países que os sediam, potencializando a atratividade turística internacional.

A captação e promoção de megaeventos, como é o caso da Copa do Mundo de Futebol da FIFA (Fédération Internationale de Football Association), que será utilizada como exemplo no decorrer do trabalho, proporcionam retorno econômico e social aos países e cidades sede que os realizam. Desta forma, os investimentos no segmento do turismo de eventos se tornam uma opção viável para impulsionar o desenvolvimento do setor.

Segundo Oliveira (2002, p. 64) dentre os segmentos desenvolvidos, esse tipo de turismo é "o mais disputado pelos países, porque nessas ocasiões os produtos turísticos são vendidos por atacado. Passagens aéreas, rodoviárias, diárias de hotéis, refeições, suvenires e serviços em geral são consumidos em larga escala”. O mesmo autor observa que tem elevada importância para a localidade que o desenvolve, com vasto campo ainda a ser explorado, visto que incentiva o desenvolvimento socioeconômico local, contribuindo para geração de empregos diretos e indiretos, renda, promove intercâmbio entre as pessoas e traz novos investimentos, além da necessidade de criação de infraestrutura que beneficia não somente o turista, mas também a comunidade receptora.

Dessa forma, os megaeventos se posicionam, diante do mercado, como uma importante ferramenta de marketing, com poder para modificar comportamentos e influenciar escolhas, transitando por todas as atividades socioeconômicas. Além da intensa contribuição na divulgação dos atrativos e recursos naturais, culturais e artificiais da localidade e da região sede do evento. Para o turismo se torna um grande negócio e uma oportunidade a ser desenvolvida.

Objetivando aprofundar a temática em questão, a seguir são apresentadas informações sobre megaeventos e sua influência nos países sede, em seguida especificamente sobre megaeventos esportivos, utilizando como case a Copa do Mundo 
de Futebol da FIFA, buscando trazer argumentos tangíveis sobre os impactos da realização de um grande acontecimento e seu poder de transformação.

\section{MEGAEVENTOS}

Muitos acontecimentos têm se transformado em megaeventos devido à sua proporção, envolvimento e magnitude. Muito em virtude de mudanças e interesses sociais, nas esferas política, econômica e cultural, além de interferências ligadas ao meio ambiente e à atividade turística, proporcionadas por esses grandes eventos. Tais proporções atingem as comunidades e seu entorno, ocasionando impactos internos e externos ao país sede do evento.

Megaeventos podem ser caracterizados como acontecimentos de curta e préestabelecida duração que apresentam:

[...] grandiosidade em termos de público, mercado alvo, nível de envolvimento financeiro, do setor público, efeitos políticos, extensão de cobertura televisiva, construção de instalações e impacto sobre o sistema econômico e social da comunidade anfitriã (HALL apud SILVA, 2006, p. $17)^{1}$.

Quanto ao porte ou dimensão, megaeventos são aqueles com mais de 5.000 participantes, de acordo com a classificação contida em Barbosa (2004, p. 107): pequeno evento, com até 200 participantes; médio, entre 201 e 500 participantes; grande, na faixa acima de 500 e até 5.000 participantes; e megaevento, com público superior a 5.000 participantes.

De acordo com Fernandes (2009), a necessidade de preparar uma cidade para sediar grandes eventos pode ser o fator motivacional necessário para a mobilização de esforços e recursos que não seriam disponibilizados ou que demandariam um período muito mais longo para se concretizarem. Estipula que neste sentido, contribui significativamente para a articulação das esferas municipais, estaduais e federal em torno da realização de um megaevento e, posteriormente da gestão de seus legados.

\footnotetext{
${ }^{1}$ HALL, C. M. Hallmark Tourist Events: Impacts, Management and Planning. Londres: Belhaven, 1992.
} 
A mesma autora tece comentários que, neste sentido, pode-se estabelecer que os megaeventos possuem poder de transformação sobre os espaços onde são realizados. Considera que resultam em clara oportunidade para o novo modelo de planejamento e gestão das cidades, calcados na lógica do mercado. Todavia, comenta que também representam uma oportunidade de se refletir e enfrentar os problemas urbanos que assolam as grandes cidades.

Dando continuidade, relata que nos últimos anos, os megaeventos, como os Jogos Olímpicos, as Copas do Mundo de Futebol, os Jogos Pan-americanos, as Exposições Internacionais, dentre outros, têm adquirido novos significados e dinâmicas. Também, que, além disso, são frutos de um novo padrão discursivo, com a convergência dos interesses públicos e privados. Especifica que embora sejam frequentemente gerados por interesses privados locais, seus custos crescentes são quase sempre financiados e garantidos por instituições públicas, de escala regional e nacional. Por fim, que o motivo seria o impulso ocasionado para a afirmação de cidades globais, para a dinamização de economias e redefinição da imagem de uma cidade e de um país no competitivo cenário mundial.

De acordo com documento organizado por Rodrigues et al. (2008) para o Ministério do Esporte, a promoção de eventos tem sido uma das principais estratégias utilizadas pelas cidades na busca de maior atração de financiamentos e investimentos. No documento tem-se que, tais eventos podem ser de diferentes naturezas, organizados por distintos atores e instituições que desempenham as mais diversas atividades na sociedade. Bem como cita, que há uma predileção especial dos gestores empreendedores pelos eventos com repercussão internacional, uma vez que poderão conferir uma imagem mais qualificada para a cidade-sede. Além disso, que os eventos internacionais podem significar a circulação de turistas com alto poder aquisitivo, dispostos a consumir os serviços e bens comercializados localmente. Ainda, que é frequente também no caso dos megaeventos proporcionarem consequências em longo prazo em termos de turismo, realocação industrial e entrada de investimentos.

Os organizadores ainda salientam que para muitas cidades os megaeventos podem ser um caminho reduzido para conseguir um reconhecimento global através da exposição de mídia, o que pode ser bom para um destino turístico caso o evento seja um 
sucesso, ou até mesmo, destrutivo caso o evento possua falhas perceptíveis para todos os participantes.

Um evento de grandes proporções, se bem planejado e sucedido poderá projetar uma imagem positiva ou renovada da cidade e/ou país sede, por meio da mídia nacional e internacional, particularmente pela cobertura de televisão.

Mas seu êxito também pode estar diretamente ligado às mudanças de comportamento da população anfitriã, à administração pública e aos organizadores envolvidos com o megaevento, que necessitam trabalhar em conjunto e harmonia.

\section{MEGAEVENTOS ESPORTIVOS}

Em um ambiente globalizado em que as distâncias parecem estar cada vez menores, resultado de fatores tecnológicos, políticos, econômicos e culturais, os megaeventos podem se transformar em uma espécie de "vitrine" da cidade ou do país que os sediam, enfatizando os seus aspectos positivos e os tornando conhecidos em nível internacional.

De acordo com Fernandes e Fernandes (2008), os megaeventos esportivos, em particular, por estarem relacionados a temáticas que despertam o interesse de um grande número de pessoas, independentemente de idade, sexo, classe social, nacionalidade ou religião, muitas vezes se tornam o único elo em comum entre nações tão distintas. Como exemplo tem-se dois dos maiores megaeventos mundiais: a Copa do Mundo de Futebol da FIFA e os Jogos Olímpicos, ambos possuindo como tema o esporte.

Conforme os mesmos autores, o esporte, enquanto prática social, envolve não apenas atletas, mas também torcedores, jornalistas, médicos, empresários, a comunidade de um local e diversos outros personagens. O esporte está arraigado e faz parte da cultura histórica da humanidade, estando contido nos valores dos seres humanos, seja da forma receptiva ou da forma ativa. É praticado em todos os continentes e produz efeitos no contexto econômico.

Por sua vez, os impactos econômicos dos eventos esportivos não se dão apenas no momento da sua realização, pois geralmente são necessários inúmeros investimentos prévios tais como construção de estádios, de equipamentos e espaços esportivos para 
efetivação do evento, além do incremento do número de meios de hospedagem e de restaurantes, de centros de entretenimento e lazer, reestruturação dos meios de transportes de acesso e de circulação e assim por diante. Contudo, pode-se verificar que os gastos, por exemplo, em função da melhoria de infraestrutura da cidade onde ocorrerão os eventos geram empregos e, consequentemente, aumento da renda, elevando, portanto, a riqueza nacional antes e após a celebração da abertura dos eventos.

Com isso, os megaeventos esportivos despertam o interesse turístico dos gestores locais, pois o turismo de eventos esportivos, entendido como "todas as atividades específicas de viagens com vistas ao acompanhamento, desempenho e participação exercidos em eventos desportivos, no país e/ou no exterior" (ANDRADE, 1992, p. 75), é responsável por diversos impactos nas suas cidades-sede, desde econômicos a ambientais. Os resultados de uma política de desenvolvimento devem considerar uma série de critérios, para que não haja prejuízos para a localidade e para a comunidade ali existente.

Fernandes e Fernandes (2008) colocam ainda que as localidades que sediam megaeventos esportivos possuem uma difícil tarefa, que requer planejamento e execução no contexto de demandas rígidas, que incluem: pouca elasticidade nos principais marcos dos cronogramas para os eventos; todos os projetos de construção (instalações e arenas esportivas, vila dos atletas e toda a infraestrutura e projetos adicionais, como novos hotéis, hospitais e opções de entretenimento) devem estar concluídos antes dos eventos; todos os aspectos do planejamento, da preparação e do recebimento dos eventos atraem muita atenção da mídia local e internacional. Os autores observam que esses e outros fatores significam que a governança, a transparência e os controles de processo se tornam cada vez mais importantes durante o planejamento, a preparação e o monitoramento contínuo dos grandes eventos esportivos.

De acordo com a mesma fonte acima, as cidades e países que sediam os principais eventos esportivos internacionais assumem compromissos financeiros substanciais com projetos de investimento de capital que devem ser planejados, financiados e concluídos em um prazo específico e inflexível. Seus autores salientam que financiar grandes eventos esportivos e a infraestrutura correspondente é um esforço que requer um grande investimento de capital, que muitas vezes ultrapassa os 
orçamentos governamentais. E que, consequentemente, muitos desses tipos de projetos envolvem iniciativas de financiamento público-privado que realocam parte dos custos de financiamento e a responsabilidade de gerenciamento de projetos e de seus riscos para ajudar a assegurar que o país-sede possa gerenciar o escopo do projeto de forma efetiva e segura.

Em contrapartida, de acordo com Barbosa e Santos (2003), existe também o lado positivo. Observam que sediar eventos esportivos globais pode gerar um grande desenvolvimento urbano e de infraestrutura, que pode ir além das instalações esportivas. Também, que projetos urbanos e turísticos podem incluir melhorias no sistema viário, de transportes, nos aeroportos, sinalização, saneamento básico, tratamento do lixo, qualidade do ar e outras, bem como na construção de equipamentos e prestação de serviços, como hotéis, restaurantes, agências de receptivo, além de significar oportunidades de melhorias na tecnologia e nos sistemas de telecomunicações.

Outro ponto tratado na mesma fonte seria o da promoção da imagem do destino, através da mídia em grande escala que estes megaeventos esportivos atraem. Seus autores mencionam que desta forma, o evento e, consequentemente, sua sede, é transmitido em nível mundial, ganhando visibilidade e propaganda internacional gratuita, transformando-se em um destino turístico potencial.

Comentam que isso ocorre através da divulgação da cultura, do idioma, dos principais atrativos turísticos, dos recursos naturais e culturais e de outros acontecimentos programados. Ressaltam que a repercussão de tal "campanha" chega a ser quase incalculável, pois a exposição do país ocorrerá em todo o mundo nos mais diversos meios de comunicação, influenciando futuras decisões de potenciais turistas em períodos posteriores à ocorrência dos megaeventos esportivos.

Complementam ainda afirmando que considerar a dimensão simbólica que esses megaeventos apresentam é fundamental para entender a acirrada competição entre cidades de um mesmo país, e de países diferentes, para sediar os acontecimentos. Isso, pois consideram que trata-se de uma oportunidade rara de veicular a imagem de uma localidade em escala global em uma perspectiva muito favorável, uma vez que a imagem está associada a grandes eventos em escala internacional. Ressalte-se ainda o forte papel que o esporte tem em muitas cidades na construção da identidade com o território. 
Para complementar, Neto (1995), relata que os megaeventos esportivos estão fortemente associados ao marketing esportivo, de tal maneira que ambas as questões devem ser trabalhadas de forma harmônica, possibilitando um grande retorno institucional. Segundo ele, há dois tipos de retornos diretos: o retorno em termos publicitário e o retorno de imagem. Por outro lado, existe um terceiro tipo de retorno que contribuiu indiretamente com um evento esportivo: trata-se da alavancagem sobre as vendas, o que acaba promovendo institucionalmente a empresa, a marca e o seu produto.

Dessa forma, nota-se que megaeventos esportivos são produtos turísticos promissores e movimentam a economia de um local, trazendo impactos de curto prazo significativos para a "indústria turística". Porém, tal viabilidade tem significados mais positivos no plano de marketing internacional do que no da economia de megaeventos.

\section{COPA DO MUNDO DE FUTEBOL DA FIFA}

Com o objetivo de discutir os megaeventos sob o enfoque estratégico da comunicação integrada e atração turística, a seguir é analisado o evento Copa do Mundo de Futebol da FIFA, para ilustrar as considerações a respeito da temática.

Segundo o sítio eletrônico da FIFA (utilizado como uma das fontes principais para os dados apresentados a seguir), a Copa do Mundo de Futebol da FIFA é a maior competição internacional de esporte único e é disputada pelas seleções masculinas principais das 208 federações afiliadas. Nele consta que a competição é jogada a cada quatro anos desde a edição inaugural em 1930, à exceção de 1942 e 1946, quando não ocorreu em função da Segunda Guerra Mundial. Ela cumpre com os objetivos da FIFA de sensibilizar o mundo, desenvolver o esporte e construir um futuro melhor de diversas maneiras diferentes.

Também se tem que no seu formato atual, a competição envolve 32 seleções que disputam o título em sedes dentro de um país anfitrião (ou países anfitriões) em um período de aproximadamente um mês. Nos três anos anteriores, são realizadas eliminatórias que definem as nações classificadas ao torneio, as quais o disputam juntamente com o país anfitrião (ou os países anfitriões). 
Com relação aos números, utilizando a mesma fonte (FIFA, 2013), apresenta-se que as 19 edições da Copa do Mundo de Futebol da FIFA foram vencidas por oito seleções diferentes. Pentacampeão mundial, o Brasil é o único país a ter disputado todos os torneios. Os outros títulos foram conquistados por Itália (quatro), Alemanha (três), Argentina (dois), Uruguai (dois), Inglaterra, França e Espanha.

De acordo com a mesma fonte, a Copa do Mundo de Futebol da FIFA é o evento esportivo de maior audiência do mundo inteiro. Nela consta que cerca de 715,1 milhões de pessoas assistiram à final da Copa do Mundo de Futebol da FIFA 2006 na Alemanha. Que o evento de 2010 na África do Sul foi transmitido a 204 países por 245 canais diferentes. E, que dentro dos estádios, 3.170 .856 espectadores compareceram às 64 partidas, com uma média de 49.670 por jogo e que foi o terceiro maior público total, atrás do dos EUA 1994 e da Alemanha 2006.

Além disso, que mais de seis milhões de pessoas participaram de eventos simultâneos com telões em 16 lugares espalhados pelo mundo: dez na África do Sul e os outros em Roma, Paris, Berlim, Sydney, Cidade do México e Rio de Janeiro.

Consta que na última Copa do Mundo de Futebol da FIFA, foram impressos 177.853 crachás de credenciamento. Além disso, que o programa de hospitalidade atraiu quase 250 mil hóspedes. Por sua vez, que mais de 750 mil litros de cerveja foram vendidos nos estádios, e 390,6 mil cachorros quentes foram comercializados em espaços abertos ao público, muitos deles aos 500 mil estrangeiros que visitaram a África do Sul.

$\mathrm{Na}$ mesma fonte se afirma que por meio de parcerias e direitos de transmissão, a Copa do Mundo de Futebol da FIFA gera importantes recursos para o investimento em atividades sociais relacionadas ao torneio. Também, que por ocasião da África do Sul 2010, foi lançada a campanha "20 Centros para 2010", que teve o objetivo de promover a saúde pública, a educação e a prática do futebol em comunidades carentes do país.

A Copa do Mundo de Futebol da FIFA também gera recursos para muitos outros programas de desenvolvimento que prestam auxílio às federações afiliadas à FIFA durante todo o ciclo de quatro anos.

As três próximas edições estarão sendo sediadas pelo Brasil em 2014, pela Rússia em 2018 e pelo Catar em 2022.

Ainda utilizando a mesma fonte como base, relata-se que as eliminatórias para a Copa do Mundo de Futebol da FIFA Brasil 2014 terão 204 países de seis continentes 
disputando 31 vagas. As 12 cidades-sedes dos jogos foram definidas no dia 31 de maio de 2009, em anúncio oficial da FIFA (2013) na cidade de Nassau, capital das Bahamas. Sendo elas: Belo Horizonte (Minas Gerais/MG), Brasília (Distrito Federal/DF), Cuiabá (Mato Grosso/MT), Curitiba (Paraná/PR), Fortaleza (Ceará/CE), Manaus (Amazonas/AM), Natal (Rio Grande do Norte/RN), Porto Alegre (Rio Grande do Sul/RS), Recife (Pernambuco/PE), Rio de Janeiro (Rio de Janeiro/RJ), Salvador (Bahia/BA) e São Paulo (São Paulo/SP).

Tanto as eliminatórias quanto a competição em si promovem intensamente o futebol e os países anfitriões. Portanto, constituem relevantes oportunidades para a disseminação do respeito, do jogo limpo e da disciplina.

Seguindo tendências internacionais, o Brasil tem sediado megaeventos esportivos continentais nos últimos anos, destacando-se os Jogos Pan-Americanos na cidade do Rio de Janeiro em 2007, se inserindo no restrito bloco de países líderes de grandes eventos globais por sediar a nova edição da Copa do Mundo de Futebol da FIFA 2014 e os Jogos Olímpicos de 2016.

Os dirigentes públicos e demais agentes envolvidos do Brasil, escolhido como país-sede da Copa do Mundo de Futebol da FIFA 2014, têm-se preparado para sediar este megaevento esportivo desde então. De acordo com Fernandes e Fernandes (2008), o momento apresenta-se oportuno para a realização de análises comparativas e avaliações que permitam contribuir na estruturação do país para o bom desempenho do receptivo durante a Copa.

De acordo com o Portal Turismo e a Copa do Mundo: Brasil 2014 (2013), com a criação do Ministério do Esporte, em 2003, o status do esporte no Brasil teve grandes mudanças, recebendo tratamento diferenciado por parte do Governo Federal, uma vez que passou a fazer parte da estrutura do Estado e constituir-se como política governamental efetiva, com destaque para um conjunto de programas e ações concretas relacionadas às práticas esportivas. Com isso, as ações de preparação da Copa do Mundo de Futebol da FIFA acabaram sendo beneficiadas.

Como citado pela mesma fonte, no contexto do Plano Nacional de Desenvolvimento do Esporte, a captação e a realização de megaeventos esportivos em cidades brasileiras, a partir, sobretudo de uma ação determinada dos governos, adquiriram maior centralidade num momento singular da história esportiva do País. A 
realização com êxito dos Jogos Pan-Americanos e Parapan-Americanos de 2007 evidencia os diversos benefícios que podem ser alcançados e que devem ser revertidos para toda a sociedade nas cidades sede, nos Estados e no País. A infraestrutura, o conhecimento, a tecnologia, entre outras áreas mobilizadas para a realização de um grande evento podem potencialmente viabilizar o acesso de camadas significativas da população às políticas públicas em diversas áreas.

Ainda utilizando esta última fonte citada, relata-se que o país poderá aproveitar a oportunidade da exposição internacional para acrescentar algo à tradicional imagem de sol e praia. Evidenciar seu potencial multicultural e acolhedor, reforçar ou mesmo criar sua infraestrutura urbana para melhor mobilidade dos hóspedes, como uma boa rede pública de transportes, alargamento e modernização de avenidas, reforma das estruturas aeroportuárias, ampliação da rede hoteleira, esportiva e da rede básica de saneamento e assim por diante, de modo a transferir aos habitantes, posteriormente, podendo ser alguns dos benefícios advindos dessa oportunidade.

Esses foram alguns dos motivos que levaram dirigentes, empresários e autoridades do Brasil a se unir e se candidatar para ser sede da Copa do Mundo de Futebol da FIFA 2014, podendo trazer diversas mudanças e benefícios para o país.

\section{CONSIDERAÇÕES FINAIS}

Neste artigo se procurou mostrar que os megaeventos esportivos podem ser uma estratégia viável para estimular a atratividade turística de uma localidade, região ou país, argumento embasado por meio dos seus efeitos ambientais, culturais, econômicos, políticos e sociais nas cidades que os sediam, gerando uma série de inter-relações e projetos, que ao serem implementados causam impactos positivos e/ou negativos nos vários segmentos da sociedade.

A realização de um desses megaeventos pode proporcionar o desenvolvimento sociocultural da comunidade em que estará inserido, através da necessidade de troca de informações, da atualização de tecnologias e do debate de novas proposições, projetos e ações que podem se implementados para agregar benefícios sociais e econômicos vinculados ao acontecimento. Se bem realizados, os megaeventos promovem interação 
entre as pessoas, contribuem para geração e fortalecimento das relações sociais, industriais, culturais e comerciais, e trazem benefícios econômicos, agregados ao aumento de receitas dos diversos setores envolvidos e a geração de empregos.

Para os países sede de uma Copa do Mundo de Futebol da FIFA é a oportunidade de desenvolver-se no que tange à modernização e apresentar não só sua capacidade de organização, como também força econômica para captar investimentos e divulgar os seus atrativos que poderiam transformar as cidades sede em promissores destinos turísticos antes, durante e após a realização do evento.

Diante da oportunidade, o planejamento pautado por objetivos claros e pelas demandas locais não pode ficar em segundo plano, sob pena de a imagem de uma cidade não apresentar aspectos positivos, gerando problemas e afastando tanto o turista estrangeiro como o investidor internacional que se quer atrair. Para que o saldo do evento seja positivo, muitos desafios devem ser superados e as cidades e os estados que irão sediar um megaevento precisam planejar desde o início um longo processo de realização de obras, de ações de marketing e de desenvolvimento de ações de diversas ordens.

\section{REFERÊNCIAS}

ANDRADE, J. V. de. Turismo: Fundamentos e dimensões. São Paulo: Ática, 1992.

BARBOSA, C. M. B. Estratégias de captação e organização de eventos: um estudo de caso na agência Idéias Eventos e Promoções Ltda. Graduação (Curso de Turismo) Universidade Federal do Rio Grande do Norte, Natal, 2004.

BARBOSA, L. G. M.; SANTOS, R. L. Jogos Pan-Americanos 2007 - Compreensão dos impactos a busca de uma estratégia para maximizar os benefícios. 2003. Disponível em: $\quad<$ http://www.braziltour.com/site/br/dados_fatos/conteudo/ver.php?in_ secao $=311 \&$ idConteudo=21 $>$. Acesso em: 20/04/2010.

FERNANDES, A. C. B. Além do Gramado: a influência de um megaevento na imagem de uma cidade sede. Porto Alegre, 2009. Disponível em: <http://www.lume.ufrgs.br/bitstream/handle/10183/22323/000739600.pdf?sequence=0> . Acesso em: 27/03/2010. 
FERNANDES, F.; FERNANDES, A. Megaeventos Desportivos e Renovação Urbana Como Fatores de Indução ao Desenvolvimento Turístico. São Paulo: 2008. Disponível em:

<http://www.uniban.br/pesquisa/iniciacao_cientifica/pdf/ciencias_humanas/admneg/me gaeventos_turistico.pdf $>$. Acesso em: 07/04/2010.

FIFA. Fédération Internationale de Football Association. Disponível em: $<$ http://pt.fifa.com>. Acesso em: 01/06/2013.

NETO, F. P. M. Marketing Esportivo. Rio Janeiro: Record, 1995.

OLIVEIRA, A. P. Turismo e desenvolvimento: planejamento e organização. 4. ed. São Paulo: Atlas, 2002.

PORTAL COPA 2014. Disponível em: <www.copa2014.org.br>. Acesso em: 01/06/2013.

RODRIGUES, R. P.; PINTO, L. M. M.; TERRA, R.; DACOSTA, L. P. (Orgs.). Legados de Megaeventos Esportivos. Brasília, 2008. Disponível em: <http://www.confef.org.br/arquivos/legados/Livro.Legados.de.Megaeventos.pdf>.

Acesso em: 02/04/2010.

SILVA, J. Segurança em Megaeventos Esportivos. In: DACOSTA, L. P. (Org.) Atlas do Esporte no Brasil (versão digital), Porto Alegre: CREF2, 2006. Disponível em: <www.atlasesportebrasil.org.br>. Acesso em: 13/04/2010.

Recebido em: 18-08-2013.

Aprovado em: 17-09-2013. 